\title{
Properties of Body Segments Based on Size and Weight ${ }^{\prime}$
}

\author{
WILFRID TAYLOR DEMPSTER AND GEORGE R. L. GAUGHRAN \\ Department of Anatomy, The University of Michigan, Ann Arbor, Michigan \\ and Department of Anatomy, The Ohio State University, Columbus, Ohio
}

\begin{abstract}
Values are presented for body constants based on a study of nine male white cadavers of normal appearance and average build. The limb data are supplemented by a further analysis of 11 upper and 41 lower limbs. Techniques used in the study form standard procedures that can be duplicated by subsequent workers. Each cadaver was measured, weighed, and somatotyped. Joints were placed in the midposition of the movement range and the body was frozen rigid. Joint angles were bisected in a systematic dismemberment procedure to produce unit segments. These segment lengths were weighed, measured for linear link dimensions, and analysed for segment volumes. The segment centers of mass were located relative to link end points as well as in relation to anatomical landmarks. Finally, each segment was dissected into its component parts and these were weighed. The specific gravity of each body part was calculated separately. Data are expressed in mean values together with standard deviations and, where available, are correlated and evaluated with other values in the literature.
\end{abstract}

Data on the relative bulk of body segments have been scarce. Until recently, the only users of information dealing with the mass and proportion of the human figure have been sculptors and graphic artists. These people usually met their needs through canons of proportions and a trained perception rather than by actual measurement. There are no substitutes though for good empirical data when critical work on body mechanics or accurate analyses of human locomotion are attempted. During the past decade or so, the need for such information has been recognized specifically in designing prosthetic and orthotic devices for the limbs of handicapped persons, for sports analysis, for the construction of test dummies, such as those subjected to vehicular crashes, and for studies on the dynamics of body impacts in crashes and falls. The fundamental nature of data on the mass and dimensions of the body parts cannot be questioned. It is odd that even now there is such a dearth of information.

The research literature up to the present contains usable body segment measurements from only 12 (or possibly 14) unpreserved and dismembered cadavers, all adult white males. A tabulation of data in an Air Force technical report (Dempster, '55a), dealing with seven specimens ca- daver by cadaver, was the first amplification of the scanty records in more than two generations. The tables on Michigan cadavers were reprinted by Krogman and Johnston ('63) in an abridgment of the original report; Williams and Lisner ('62) presented their own simplifications based on the same study; Barter ('57), Duggar ('62) and Contini, Drillis, and Bluestein ('63) have made tallys of data from the original tabulations along with parts of the older data. None of these studies gave any attention to the procedural distinctions between workers who had procured original data; one even grouped volumes and masses indiscriminately as masses. The Michigan data, however, have not been summarized nor evaluated up to this time. Since the procedures and, especially, the limiting conditions incidental to the gathering of body-segment data, have not been commented on critically since Braune and Fischer (1889), a comprehensive discussion of the entire problem at this point should help further work in this important area.

1 Supported in part by research grants from the 1 Supported in part by research grants from the
Public Health Service National Institutes of Health Public Health Service National Institutes of Health (GM-07741-06), and from the office of Vocational Re-
habilitation (RD-216 60-C), with support a dozen years earlier from a research contract with the Anthropometric Unit of the Wright Air Development Center, Wright-Patterson Air Force Base, Dayton, Ohio (AF 18 (600) -43 Project no. 7414). 
The present study, therefore, has a four-fold function: (1) to summarize statistically the above mentioned (Michigan) raw data and make minor corrections, (2) to correlate and evaluate these findings with those of others, if appropriate, (3) to present additional information relevant to the segment volumes of cadavers, and (4) to suggest both problems and techniques to future investigators, especially those located where cadavers are more readily available. These objectives require critical and interpretive comment about the earlier studies and about some aspects of our techniques.

\section{Previous studies}

Since earlier authors derived body mass data in diverse ways, one must either select the work of one author and ignore the rest, or make an attempt to consolidate and salvage parts of the scanty data. The latter procedure, however, is subject to question when records from different authors are pooled indiscriminately as was done by Barter ('57). In order to correlate old data with more recent work, it is necessary to examine the several procedures for dismemberment in some detail. The order of magnitude of difference in data caused by sawcuts, for example, may be quite significant. One sawcut might remove material from one segment and add it to the adjacent one, whereas another cut might do the reverse. Thus the locations of the center of mass (center of gravity) in a segment may be inconsistent in two groups of data unless allowances are made for the dismemberment procedures used.

The first attempt to obtain comprehensive data on cadaver segments was that of Harless (1857, 1860). Although Harless was a physiologist, his research on body segments related to his lectures and text on art anatomy (1857). Harless dismembered and measured the parts of two male cadavers. The subjects were executed criminals; heheaded, and consequently drained of blood. The mass and center of mass of the head were determined from the severed part, arbitrarily defined as it was by the beheading procedure and the rationale of some other procedures were equally questionable. The soft tissues of the hip were cut transversely at the joint level and then below this were separated from the lateral face of the pelvis; the joint capsule was encircled by a cut, and the femoral head was simply disarticulated. The shoulder mass was disarticulated after two knife cuts: (1) a vertical cut through the axillary folds and (2) a horizontal cut below the acromial process. The more distal joints of the limbs in extension were sawed through at joint centers at the femoral condyles, at the malleoli, at the humeral condyles, and distal to the ulnar styloid process. Harless described a method of locating joint centers in the living by making triple exposure photographs with the limb in three positions against a dark red background; it is not clear how he located joint centers in the cadavers. Skin flaps at the two ends of a segment were stretched over the cut surface and stitched like amputation stumps to compensate for nonuniform retraction of the soft tissues at the cuts. Harless determined the linear dimensions, the masses, and the centers of mass of the several segments. He also attempted to locate the center of mass of the trunk section by a crude mathematical approximation. The living weight of one subject was obtained before execution; that of the other was taken as the sum of the dismembered parts, corrected by the percentage of loss of blood in the first subject. It is somewhat difficult today to evaluate Harless's measurements in terms of later data. Linear measurements given in hundredths or thousandths of centimeters are technically unrealistic. Harless's research plan was too limited to yield many useful measurements for body mechanics. His simple calculations of trunk mass, for example, involved density correction for the total body rather than for the thoracic and lower trunk sections, and his determinations of centers of mass located them only along the lengths of the segments. Braune and Fischer (1889) criticized Harless's method for obtaining the latter information since it involved suspension of flabby, non-rigid parts. As a subsidiary part of Harless's paper on body segments, he measured the specific gravity (density) of the limb segments of his second speci- 
men and those of five other subjects, including females.

During the latter half of the nineteenth century, anatomists and pathologists recorded the mass and specific gravity of numerous body organs, as summarized by Vierordt (1893). More recent tabulations (Spector, '56) show no appreciable increase in this type of data. The first to mention the masses of the head, trunk, and limbs was Krause (1843), and Meyer (1873) used these masses for calculations. By using simple geometrical figures with human dimensions, Meyer estimated the center of mass for the body in various postures. Valentin (1850) tabulated the masses of the head, limbs, and certain viscera for three newborn infants.

In 1884, Meeh (1895) dismembered and measured masses and volumes of the parts of four infants: one premature, two newborn, and one in its second year. (The data were prepared for publication by Voit in 1895). The upper limb segments and the leg and foot were prepared by the same dismemberment procedures used by Harless. The rest of Meeh's technique correlated with procedures that he developed for the measuring of volumes in adult living subjects. In the latter method a subject stood upright in a special tank and water was introduced to predetermined levels, so that horizontal volume levels could be measured by water displacement. To measure the head volume, the subjects immersed their heads below the water surface of the tank to predetermined landmarks. Meeh's dismemberment procedures on infant cadavers were intended to produce parts on which both volume and mass could be determined corresponding to the levels he had defined on adults. Thus, the heads of infant cadavers were severed obliquely by three sawcuts from the external occipital protuberance: (1) to the supraorbital line, (2) to the lips, and (3) to the hyoid bone. Similarly, the trunk and the thighs of the infant cadavers were cut into several transverse zones.

Most of Meeh's attention was given to determining ratios of the volumes (or masses) of the parts to the total body volume (or total body mass), and to comparisons of infant volumes (or masses) with those of adults. Although Meeh measured masses and volumes on his infant material, it should be noted that he was not concerned with functional body segments. He did not calculate specific gravities, and he did not locate centers of mass.

One cannot now read the data of Krause, Valentin, and Meeh out of context; the data do not provide useful information of a mechanico-functional sort. This is true also of numerous measurements of body volumes in boys of different ages by Zook ('32), who in a growth study immersed standing subjects in water to different surface landmarks and measured the weights of water displaced.

If the volumes of body segments are to have any validity for correlations with mass segment data for mechanical analy. ses, the segments must correspond with the segments that move as a unit in body actions and they must be corrected for segment density - data so far obtained only by Harless and by Dempster. Apparently only Dempster ('55a) has made volume measurements of the segments of 38 living subjects using several specially built tanks and water immersion of limb segments held at approximately midrange postures. Other authors (Meeh, 1895; Contini, Drillis, and Bluestein, '63) who have measured the volumes of limbs held vertically in a standard vertical tank must arbitrarily define segments by the water level; but the proximal ends of the arm and thigh segments cannot be defined meaningfully by a horizontal level at the axilla or groin unless the trunk is bent sharply relative to the limb.

In an initial report by Braune and Fischer (1889), data were taken from three fresh (unpreserved) cadavers that were frozen in the supine posture and dismembered by sawcuts through the joint centers. The dismembered parts remained frozen and rigid throughout all the procedures involved in sawing, measuring dimensions, weighing, and locating the centers of gravity. The cadavers were frozen on boards, supine and extended; Braune and Fischer intended to separate the joints as nearly as possible across "functional" hinge axes.

In accord with the latter intention, Braune and Fischer made their cuts as 
follows: (1) shoulder - by a sagittal cut through the armpit toward the center of the humeral head; (2) elbow - through the axis of the humeral condyles; (3) wrist - by a transverse cut through the head of the capitate bone; (4) hip - by an oblique cut along the side of the pelvis as nearly as possible parallel to the inguinal ligament and through the head of the femur; ${ }^{2}$ (5) knee - by a transverse cut through the axis of the femoral condyles; and (6) ankle - by a transverse cut through the axis of the talocrural joint. The head was sawed by a straight oblique cut from below the chin to the rear of the skull including the upper three or more cervical vertebrae. The remaining torso was handled as a single block without further dismemberment.

Several comments on the methods of Braune and Fischer are appropriate at this point. First, there are ambiguities in their description of the dismemberment procedures used for the upper limbs. Thus, the amount of forearm supination or pronation was not clear from the text and the comment that the fingers were "half-flexed" is vague; both these factors have a relation to the distribution of mass and the location of the center of gravity of the part.

Secondly, a more general criticism applies to the whole of Braune and Fischer's procedure. In determining landmarks for their sawcuts, they moved each joint and estimated the locations of hinge axes, marking these locations before they froze the cadavers. However, this technique is less sophisticated than it appears since functional hinge axes shift position from moment to moment over a vaguely defined region and are not fixed in space like the axis of a door hinge (Dempster, '55a, b). Nominal bending axes, given with reference to well defined anatomical landmarks and relating to mean centers of curvature of the convex joint component, should be used rather than the crude, functionallyestablished pivot points used by Braune and Fischer. Methods of defining nominal axes for dismemberment procedures will be indicated below.

Braune and Fischer next weighed the rigidly frozen blocks resulting from the operations described above. In order to determine centers of mass for the segments, each block was suspended from metal pins or rods driven into the mass. Vertical marks in the plane of two plumb lines attached to the pins were made on the skin at appropriate steps in the following procedure: Each frozen segment (1) was suspended crosswise on a pin near the plane of balance, and the first skin marks were made; (2) the segment was then suspended from pins that would establish plumb-line reference planes at about $90^{\circ}$ to the first, transverse plane, and these planes were in turn marked in a comparable way. The intersection of the three planes, as indicated by marks on the skin, determined the locus of the center of mass of the part; a transverse sawcut through the intersection point then permitted the location of the center to be defined relative to the anatomy of the section. The segments remained rigidly frozen throughout all these operations.

Braune and Fischer noted that the centers of mass of the limb segments fell on, or near the line connecting the centers of joints at each end of the segments. Then, the authors determined the locations of both the joint centers and centers of mass of one cadaver in terms of Cartesian coordinates. They found that with only slight positional adjustments of the limb segments, all joint centers and all centers of mass (except those of the feet) could be aligned in a single frontal plane. It was found, furthermore, that a man could actually stand with this limb joint posture. By summating the moments of the different centers of mass for this posture in the cadaver, relative to an axis in the plane of reference, ${ }^{3}$ the center of mass of the whole body could be located as accu-

2 After several trial sawcuts on preserved cadaver material with straigtened hip joints, we interpret this section as one that just misses the anterior superior section as one that just misses the anterior superior
iliac spine, the pubic tubercle, and the ischial tuberiliac spine, the pubic tubercle, and the ischial tuberof the limb mass, including parts of the gluteus maximus, gluteus medius, gluteus minimus, and quadratus femoris muscles, and the fatty tissues of the more medial part of the buttock.

3 That is: the sum of the moments of the separate segments with reference to some arbitrary axis in the plane of reference - moments of the segments are their masses times the distances between their centers of gravity and the axis of reference - when divided of gravity and the axis of reference- when divided by the sum of the masses, gives the distance of the calculation regarding the moments about another axis at a right angle, gives the location of the center of gravity in the plane of the two axes; a further calculation relative to the third rectangular axis located the center of gravity in space (Braune and Fischer, 1889). 
rately as by balancing the body experimentally on a board.

The center of mass of the whole body could also be located by similar calculations in terms of three-dimensional coordinates for various postures in which the limbs were displaced. The data on this one cadaver, in fact, have formed a basis for studies on locomotion by Fischer ('04), Bernstein ('35), and Elftman ('39). It might be noted also that graphical and geometric methods, in addition to the more usual algebraic methods, were developed by Fischer (1892), for locating whole-body and composite centers of gravity if masses and locations of the segmental centers were known. Meyer (1873) had previously attempted this, but in a less sophisticated fashion.

An additional paper by Braune and Fischer (1892) dealt with measurements of the moments of inertia for some of the segments of the limbs of two additional cadavers. Incidental to this work, and without comment, the two authors tabulated the masses and the linear locations of centers of gravity relative to joint-centers of the segments. Presumably, the dismemberment procedures followed their earlier methods. A later publication by Fischer ('06) tabulated data concerning the second body studied in the momentof-inertia paper (Braune and Fischer, 1892), along with miscellaneous data from their 1889 paper. From a close reading of the tabulated data, it seems clear that Braune and Fischer actually presented data pertinent to statics, but differing in degree of completeness, on five bodies, plus moment of inertia data on two of these. Where appropriate, the scanty data of Braune and Fischer will be grouped with or compared to our own material in the following pages.

Fujikawa ('63) dismembered five adult Japanese bodies including two females: one specimen was unpreserved, the others were embalmed. Centers of mass were located and segmental masses were measured. A sixth head was used in locating the surface landmarks of the center of mass. The applicability of certain tabular data is unclear since the treatment was both brief and complicated by linguistic idiosyncracies.
MATERIAL

The present data were gathered in 1952 1953 and 1962 on seven unpreserved and two embalmed white male cadavers. The two preserved specimens were the first and last bodies utilized in the study; with the first, definitive methods were developed, before any work was done on unpreserved material; the other was used for illustrations and for certain miscellaneous checks performed as the present manuscript was drafted; routine data also were obtained from both. Eleven additional upper and 41 lower limbs were studied concurrently for details. All material was obtained from white, male cadavers of normal appearance. Details relating to the seven unpreserved specimens will be given first.

On receipt at The University of Michigan Anatomy Morgue, each potential specimen was photographed if it seemed tentatively acceptable. Three views were made of the body in a suspended posture; weight and supine stature were measured. Since the Michigan Anatomical Law (prior to 1958) forbade use of cadavers during the first ten days following receipt, the bodies were stored for at least this period in a cold room before they were available for dissection. During this interval, the cadavers were screened as described below, to eliminate abnormal material; meanwhile, some 60 standard caliper, tape and anthropometer measurements were made. These were intended primarily for later use as a check on further measurements of body segments pertaining to joint centers and centers of mass. The three photo views of each body were used for determinations of Sheldon somatotypes; in addition, they were enlarged to about one-seventh life size and some supplementary measurements and checks of the anthropometric measurements were made from the enlargements.

The seven unpreserved white male cadavers ultimately dismembered and summarized in this study consisted of two adults of unknown age and five between 52 and 83 years (avg. 69 years); the average height, measured supine was 67.0 inches with a range of 61.4-73.5 inches (or $169 \mathrm{~cm}$ avg., range $155.3-186.6 \mathrm{~cm}$ ); and the average weight was $134 \mathrm{lbs}$. with 
a range of 109.3-159.5 lbs. (or $61.1 \mathrm{~kg}$ avg., range $49.8-72.0 \mathrm{~kg}$ ).

We avoided cadavers for which the death certificate indicated tuberculosis or wasting diseases; mutilated or deformed bodies were likewise rejected. The cause of death was unknown for one subject; another was a death following surgery for an esophageal carcinoma; the others died of cardiovascular diseases.

The bodies were of average build for their age; Sheldonian somatotypes (Sheldon, Stevens, and Tucker, '40; Sheldon, Dupertuis, and McDermott, '54) were assessed by Prof. C. W. Dupertuis, of Western Reserve University, from the above-mentioned photographs which showed the cadavers suspended by tongs from their acoustic meati. Somatotype was used as a criterion for rejecting specimens that were not of more or less average build. (The first somatotype component in each case, following the classification scheme of Sheldon, was either 3 or 4 ; the second component was either 2,3 , 4 , or 5 ; and the third was either 2,3 , or 4 .)

The work on a given specimen involved a team of 5 or 6 persons, including student help, and usually required a three day session. Consequently, work periods had to be planned for vacations, midyear recesses, or summers. Because of the erratic supply of cadaver material suitable to our purposes, incoming specimens were screened as described above during the 10 to 20 days prior to a feasible work period. Thus, the cadavers were in cold storage prior to dismemberment from ten to as much as 20 days after receipt at the morgue. The interval between death and actual data-taking varied between two and four weeks - including the period of storage in our morgue and a period prior to receipt of the body. The few days of custody by morticians or hospitals immediately after death would normally involve refrigeration.

All measurements and procedures on the two embalmed cadavers were comparable to those described for the unpreserved specimens, although in minor ways the attention to details was different. Because the bodies were preserved, for example, there was no need for freezing of body parts, and the material offered no possible health hazard for personnel. Since joints were rigid, incisions and minor dissection were sometimes required to locate bony landmarks accurately or to increase joint mobility. The pertinent data for the two preserved bodies are: Specimen $a$ (the initial specimen) age, 67 years; supine stature, 66.5 inches $(168.9 \mathrm{~cm})$; weight, $113 \mathrm{lbs}$. (51.24 kg); somatotype 4-5-21/2; cause of death, unknown; Specimen $b$ (the final specimen) age, 70 years; supine stature, 67.7 inches $(172.0 \mathrm{~cm})$; weight, $161 \mathrm{lbs}$. $(73.0 \mathrm{~kg})$; cause of death, coronary insufficiency.

The subjects were of normal build, but elderly and most were below average in stature and weight as compared to present national population statistics. The nineteenth century investigators apparently had younger, heavier, specimens. One of Harless's Munich subjects was a "young, executed man"; the other subject was age 29. Of Braune and Fischer's five Leipzig subjects, the ages of two are listed as 45 and 50 years; the ages of the others are not given. The German authors especially mentioned certain subjects as being "muscular" or "well-built," but the only way we can compare the builds of their subjects and the Michigan series is through a height-weight ratio. The height-to-cuberoot-of-weight indices of the present group of subjects, calculated in the metric system, varied from 41.5 to 45.0 (medium builds); plus one of 46.2 (a more slender build). Indices of the five Leipzig subjects ranged from 41.4 to 43.6 , while the two Munich subjects showed indices of 43.2 and 46.5 .

It should be obvious that information based on so meager a sampling of subjects must be applied to other populations with discretion; prudently treated, of course, even sketchy data on one or two subjects may have value for first approximations. Except for the limited data of Fujikawa ('63) none of the usable cadaver information on body segments was derived from infants, children, females, or different races or builds. An examination of the data themselves, however, will show the variability and consistency of the available measurements. It should also suggest the special characteristics of the research material and the degree of confidence one 
might expect from extrapolations to living subjects of different height, weight, build, or tissue composition.

\section{PROCEDURES}

Plan of dismemberment. In this study of cadaver material, the attempt was to obtain the maximum possible amount of data from every specimen. Consequently, each cadaver was subjected to a battery of standardized procedures including: (1) screening, selection, and preliminary measurement; (2) preparation for dismemberment according to a pattern believed to be functionally meaningful; (3) the actual separation and weighing of segments; (4) measurement of the linear dimensions of segments; (5) location of segment centers of mass; (6) determination of segment volumes; and (7) determinations of the specific gravity of tissue. In addition, (8) measurements were made of the frequencies of segments considered as pendulums. The latter data, along with segment lengths and masses, permit determinations of radius of gyration and moment of inertia of segments, factors pertinent to dynamic analyses. (The data dealing with radius of gyration and moment of inertia will be treated in a later paper.) The different phases of the procedure were often handled concurrently with a designated person under supervision assigned to each activity.

The procedures for dismemberment were based on the following rationale. Since segments are in fact continuous, any separation of segments is arbitrary. It is obvious that the soft tissues of such parts as the head, thorax, forearm, foot, and so on, move en masse with the more-or-less rigid elements of the body framework, but these units cannot be separated for measurement simply by cutting through the soft tissues and disarticulating joints. A more fundamental understanding of body mechanics is required if the parts measured are to be meaningfully defined.

The links or straight-line distances that span between adjacent joint centers make up the effective core-lines of the body segments. The length of each link is related to the solid structural element or elements in a segment that provide the lever system of the body mechanism. (The link concept has been developed in detail by Dempster, '55a, b, '61, '65, and Dempster, Sherr and Priest, '64.) Each link in the body is enveloped by such tissues as skin, muscles, and bone, and the composite becomes a mass segment. But the link, like the link in a machine, is the structural unit or functional length of such a unit necessary for any valid consideration of body mechanics. A body segment length is the same as its link, and this length, rather than a length from arbitrary surface landmarks, is needed in locating center of mass or in determining radius of gyration and moment of inertia. Consequently, segments must be separated at joint-centers rather than at joint-surfaces.

Braune and Fischer (1889) separated joints at joint-centers and they described their technique in some detail. In contrast, Harless (1860) dismembered certain limb segments of his specimens by disarticulating the joints but he cut other joints at joint-centers; he spoke, however, of segment lengths as from joint center to joint center. Meeh (1895) also disarticulated joints in his work, following Harless's method.

Braune and Fischer sawed across frozen, straightened limb joints of the supine body at the level of the joint centers. Our basic plan, in contrast, was to freeze joints at the midposition of their movement range, relative to all possible directions of movement, and to bisect the resulting jointangles by sawcuts through joint centers. Our assumption was that separation across either straightened joints or fully-flexed joints would divide the segments into masses that would not be representative of a large range of joint postures; the bisecting of a joint angle by sawcuts across a midrange position, however, should provide a meaningful compromise for the sepration of mean segment masses.

Initial dismemberment techniques. Each cadaver was lashed to a work board, and hip and shoulder joints were bent to their midrange positions (fig. 1A). Thus, the humerus was flexed $60^{\circ}$, abducted $45^{\circ}$ and medially rotated $23^{\circ}$; the thigh was flexed $57^{\circ}$, abducted $10^{\circ}$ and laterally rotated $3^{\circ}$. A protractor with a movable arm was used to set up these midrange postures based on joint-range measurements of liv- 


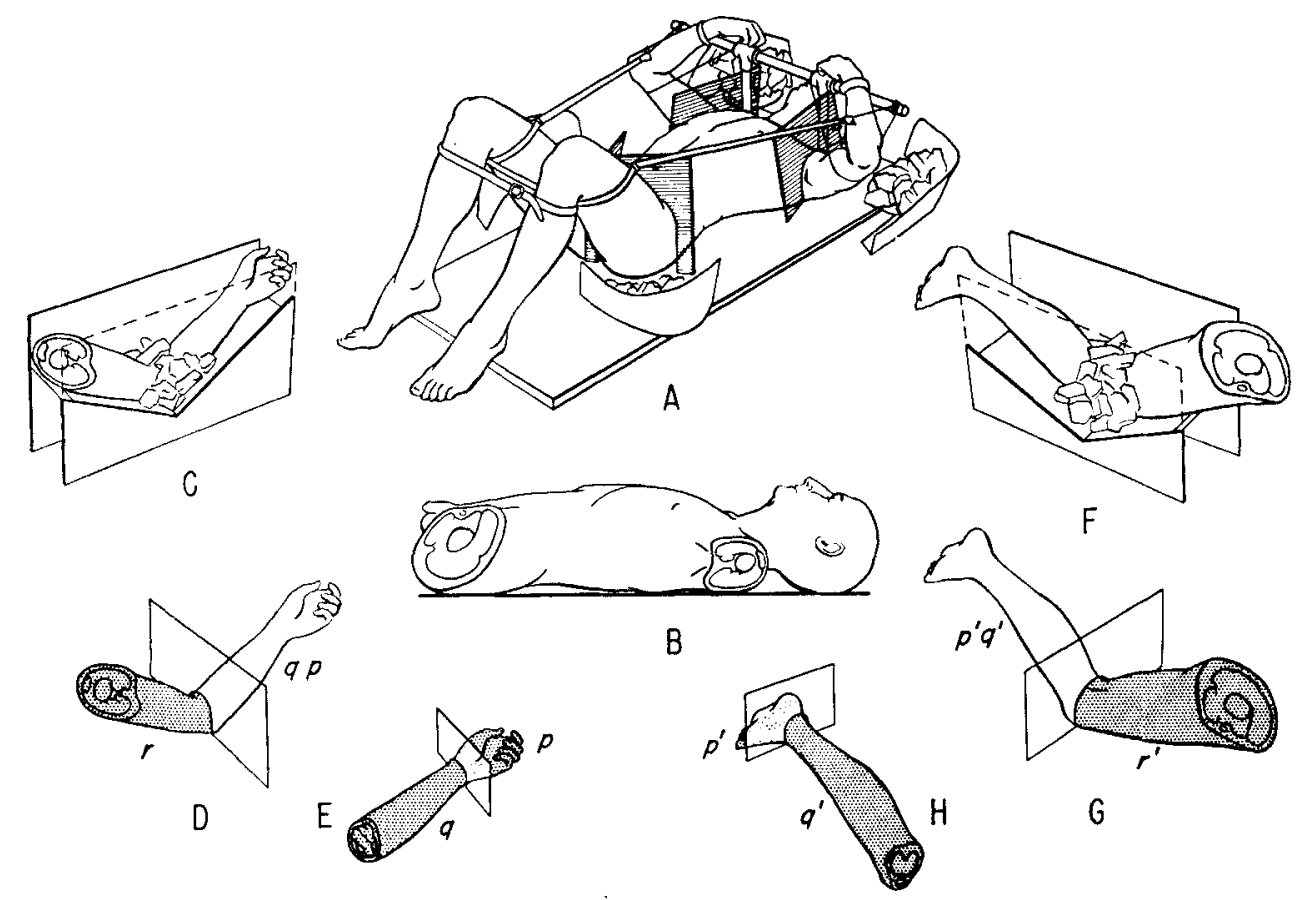

Fig. 1A A cadaver with the hips and shoulders trussed into midrange positions. Sheet metal containers about each joint are heaped with dry ice. Shaded planes show where sawcuts were made to bisect the midrange joint angulations. $\mathbf{B}$, The head and trunk section after removal of limbs. $\mathbf{C}$ and $F$, Whole upper and lower limbs in special troughs with dry ice to freeze elbows and knees in a semiflexed midrange position. $D$ and $G$, Planes show location of sawcuts that bisect the midrange joint angulations. $E$ and $H$, Planes of sawcuts at wrist and ankle. Segments coded with single letters, $p$, $q$, and $r$ (or $\mathbf{p}^{\prime}, \mathbf{q}^{\prime}$, and $\mathbf{r}^{\prime}$ ), or stippled, are unitary segments; whole limbs and composite distal segments ( $q, p$, and $\mathbf{p}^{\prime}, q^{\prime}$ ) are not stippled.

ing subjects (Dempster, '55a). To simplify bending at the hip joint and to assure accurate localization of the femoral head, an incision between the scrotum and thigh was continued down to the ischiopubic ramus; each of the muscles arising from the outer aspect of the ischium and pubis was then dissected from its periosteal attachment and from the obturator membrane. This procedure facilitated positioning of the hip joint and accurate palpation of the femur head. Similar probing incision to permit accurate location of the humeral heads were also made through the deltoid muscles. Once positioned, the limbs were secured with rope to posts on the work board. Dry ice (solid carbon dioxide) was then packed about the four joints (fig. 1, A) and the body, trussed in this manner, was placed in a cold room overnight.
The joints, frozen solidly in position, were severed by saw cuts the next morning to provide five body parts for subsequent procedures: trunk-with-head, right and left upper limbs, and right and left lower limbs, (fig. 1B, C, F). Surface landmarks which defined the plane of the sawcut at the shoulder (fig. 2A, B) were: (a) a point on the anterior axillary fold immediately superficial to the medial contour of the arm, (b) a similar point on the posterior axillary fold, and (c) the palpable sulcus between the bones at the acromioclavicular joint. These points define a plane which simultaneously bisects the midrange angle of the joint and passes through the center of the head of the humerus.

Landmarks for our saw plane through the hip joint (fig. 2B) were: (d) a point on the skin at the symphyseal end of the ischiopubic ramus at the origin of the ad- 
ductor longus muscle, (e) along the ischiopubic ramus to the ischial tuberosity and to the origin of the hamstring muscles, and (f) a point just inferior to the anterior superior iliac spine.

This represented a compromise plane, since a true bisecting plane for the midrange position of the hip joint will pass obliquely across the hip mass from the femoral trochanter and posttrochanteric dimple laterally - along Holden's line (an inch or two below the inguinal ligament: Jones, '20) - to an oblique transacetabular line between the anterior inferior iliac spine and the lesser sciatic notch of the ischium. If such a sawcut were used, an additional sawcut at an angle, along the outer face of the ischium and pubis, would be required to separate the limb from the trunk. It should be noted that the landmarks, and plane, actually used (fig. 2B, $d, e, f)$ represent a compromise that cuts the center of the femoral head but does not bisect the joint angle. No saw cut in a single plane will simultaneously: (1) separate the thigh from the trunk with a flat surface, (2) bisect the joint angle, (3) cut through the joint center, and (4) provide good landmarks. The hip landmarks finally chosen were decided upon because correlated measurements of limb volume on living subjects, using water-immersion techniques, were feasible with the same landmarks. Our shoulder landmarks,
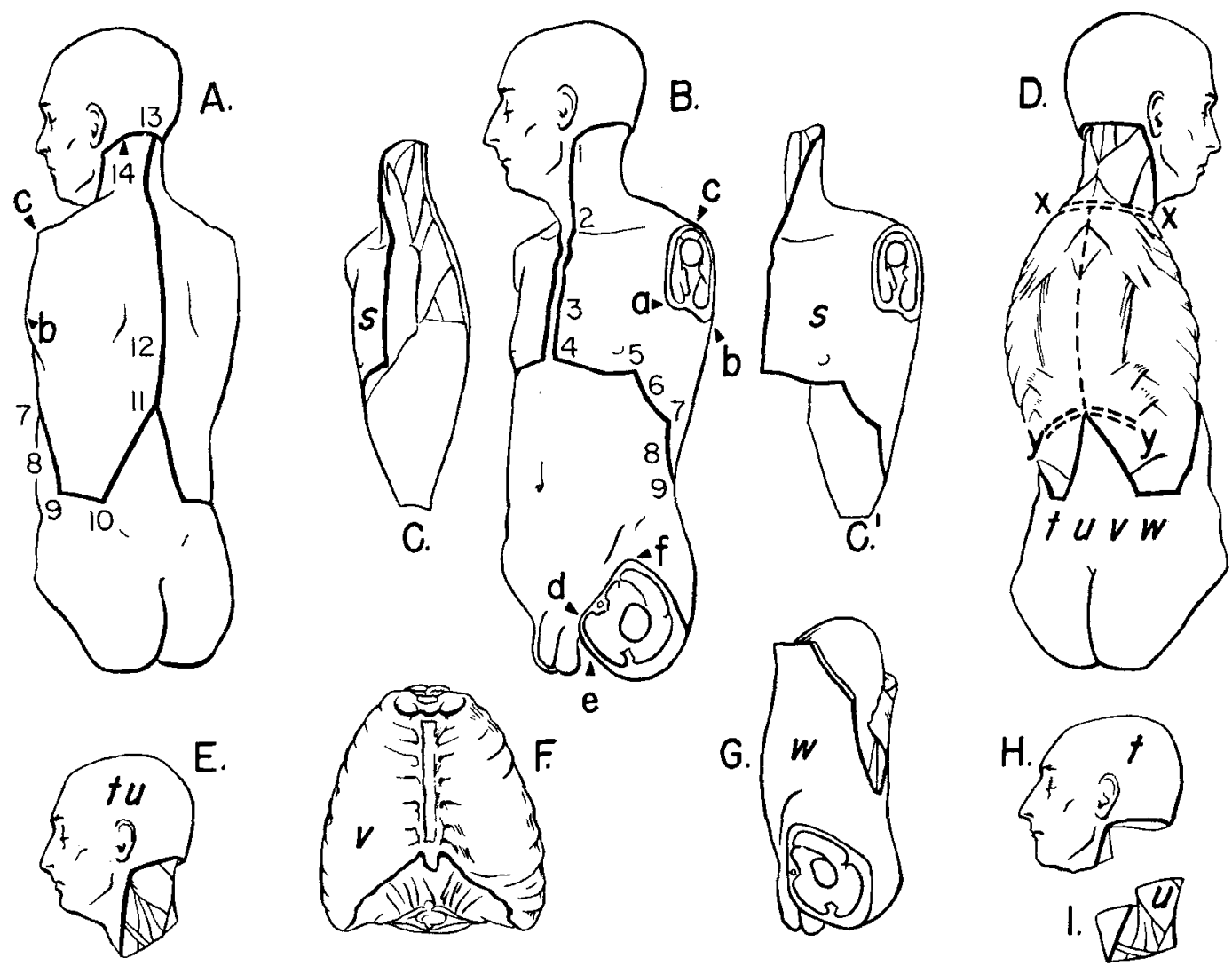

Fig. 2 Stages in segmentation of the head and trunk. A and B show a sequence of landmarks for incisions used in removing the limbs (letters) and the shoulder mass (figures). $\mathbf{C}$ and $\mathbf{C}^{\prime}$, Right and left frozen shoulder masses after removal from plaster moulds. D, Composite head and trunk section without shoulders. Lines $\mathrm{X}-\mathrm{x}$ and $\mathrm{Y}-\mathrm{Y}$ suggest the level for severing deep back muscles prior to disarticulating cervical from thoracic and thoracic from lumbar vertebrae. E, Composite head and neck segment after separation from the trunk. F, G, H, and $I$, Individual segments: Thorax, abdominopelvic complex, head, and neck. 
which required no such compromise, permitted similar measurements on living subjects for the upper limbs.

Five composite parts resulted from the first dismemberment procedure (fig. 1B, C, F). As in the studies by Harless and by Braune and Fischer, measurements were made on each of these composites, and the following cadaver-by-cadaver measurements for eight specimens (Dempster, '55a) are on record: (1) weight, (2) location of center of mass, (3) moment of inertia, and (4) volume after thawing of the limbs.

Since the Michigan data, and the older German records, too, showed considerable variation in the center of mass and moment of inertia of composite parts, a variability that could be attributed to differences in angulation of the elbow, wrist, fingers, knee, or angle, only unitary limb segments are dealt with in this paper. The dimensions, location of centers of mass, and radius of gyration of such limb composites as whole limbs, forearm-withhand, and shank-with-foot (fig. 1D, G, E, $H$ ) are better derived mathematically from unitary data than by using the variable information from direct measurements. As will be noted, however, composite parts did have indirect value in verifying the mass and volume data of unitary limb segments.

Dismemberment of limbs. The elbows and knees of the detached upper and lower limbs were bent to arbitrary midrange positions of $70^{\circ}$ and $62^{\circ}$ respectively, based on the literature concerning joint-range in living subjects (Dempster, '55a). The forearm was then given a semi-prone position, and the foot was rotated laterally until a toe-to-heel line averaged $5^{\circ}$ from the plane of knee-bending. So positioned, the limbs were placed in troughs (fig. 1C, F), and again dry ice was packed about the joints until they were frozen solid. Sawcuts were then made that passed through each joint center and bisected each joint angle (fig. 1D, G).

Anatomical landmarks defining the proper plane for the sawcuts at each elbow (fig. 1D) were as follows: (1) lower border of medial epicondyle of the humerus; (2) a point on the capitulum of the humerus (at the lateral epicondyle),
$8 \mathrm{~mm}$ proximal to the palpable groove between the circumference of the radius and the humeral capitulum; and (3) the antecubital flexure crease of the skin. Landmarks for the knee (fig. 1G) were: (1) center of the posterior curvature of the medial femoral condyle, as palpated; (2) same for the lateral condyle; (3) the midregion of the popliteal flexure crease of the skin; and (4) a point below the upper margin of the patella. Incisions through the skin with a scalpel were an aid when saw cuts were made.

Eight new limb segments were produced by the above procedure; that is, two upperand two lower-limb segments on each side. Of these, the four proximal segments were unitary, the four distal binary. In figure 1, shaded parts represent the four unitary segments; upper-limb segments are designated by the letters $\mathrm{p}$, $\mathrm{q}$, and $\mathrm{r}$; while lower-limb segments are indicated by $\mathrm{p}^{\prime}, \mathrm{q}^{\prime}$, and $\mathrm{r}^{\prime}$. The four distal segments (fig. $1 \mathrm{E}, \mathrm{H}$ ) were then severed by sawcuts at the wrist and ankle, producing eight new unitary segments (a total of $12 \mathrm{seg}$ ments for the four limbs).

In these last procedures, the intent was again to separate limb segments in accordance with the link concept; consequently, joints were positioned and frozen before cutting, and landmarks were determined to define sawcut planes that would bisect joint-angles and also pass through jointcenters. Thus, wrists were frozen unflexed and adducted about $10^{\circ}$. Landmarks beginning on the palmar aspect of the hand were: (1) midpoint of pisiform bone, (2) distal wrist crease at palmaris longus tendon, and (3) proximal palpable part of the scaphoid bone at the base of the thenar eminence; and, on the dorsum of the hand, (4) palpable sulcus between lunate and capitate bones. This cut typically passes through the center of the head of the capitate bone at approximately the functional center of the wrist joint (fig. 1E).

For similar reasons the feet were frozen with the sole of each at a right angle to the shank axis. Landmarks for this positioning were: (1) superior border of calcaneus just anterior to the Achilles tendon as palpated medially and laterally, (2) upper border of the head of the talus, and (3) lower tip of the fibula. This cut 
passes through the center of curvature of the talus bone at the ankle joint (fig. $1 \mathrm{H}$ ). Often it was convenient to transect the calcaneal tendon at its insertion to permit the foot to dorsiflex enough for freezing; skin incisions ordinarily were an aid in determining bony landmarks with certainty, and skin pencil lines or scalpel scratches were used routinely as guides for sawcuts.

During this sequence of dismemberments, some 20 limb parts were available at different times for measurement. Of these, 12 italicized here and represented with single letters were unitary segments, and eight were composites of two or three units. The parts were: right and left total upper-limbs (pqr), right and left total lower-limbs $\left(\mathrm{p}^{\prime} \mathrm{q}^{\prime} \mathrm{r}^{\prime}\right)$, right and left arms (r), right and left forearms with hands (pq), right and left thighs ( $\left.\mathrm{r}^{\prime}\right)$, right and left legs with feet $\left(\mathrm{p}^{\prime} \mathrm{q}^{\prime}\right)$, right and left forearms (q), right and left hands ( $\mathrm{p})$, right and left shanks $\left(\mathrm{q}^{\prime}\right)$, and right and left feet $\left(\mathrm{p}^{\prime}\right)$. For later measurements and center-of-gravity determinations, the fingertips were sewn flexed to the thenar eminence, just proximal to the palpable uncinate process of the hamate bone, in a radioulnar sequence approximating a "rest" position (fig. 4A).

Further dismemberment of body. Although the studies of Harless and of Braune and Fischer carried the dismemberment of the central body mass only as far as separating the head from the trunk, we separated the total trunk-with-head into five unitary parts (fig. 2): (1) right shoulder segment (s), (2) left shoulder segment $(\mathrm{s}),(3)$ head $(\mathrm{t}),(4)$ thorax (v), and (5) abdominopelvic segment (w). The pelvic mass could not be treated as a unit separable from the abdominal mass, as is commonly done in the constructive sketches of art anatomy texts, since the abdominopelvic viscera would be unrestrained if the body wall and peritoneum were transected. Composite segments (fig. $2 A, D, E)$, analogous to those for the limb procedures, were available for measurement at interim stages of the dismemberment: (1) trunk-with-head-with-shoulders (s s t u v w), (2) trunk-with-head-minusshoulders ( $\mathrm{t} u \mathrm{v} w$ ), and (3) head-withneck $(t) u)$. These composites were not contaminated by the above-mentioned errors that varied from specimen to specimen because of angulation differences in limb composities. Data on composite seg. ment (1), the trunk-with-head-withshoulders unit, may be of more value practically than those of the unitary segments of the axial region, hence, these will be presented and discussed.

The shoulder section (fig. 2A, B, C, C') was defined as the shoulder girdle and all muscles operating on the girdle, together with the overlying subcutaneous tissue and skin. So defined, the two shoulder masses fit over the upper trunk like a cape. Each side attaches to the thorax in front along a line that coincides with the origins of the pectoralis major and serratus anterior muscles. Posteriorly, the girdle muscles of each side attach to the rear portion of the skull, to the vertebral spine, to the thoracodorsal (lumbodorsal) aponeurosis, and to the crest of the ilium.

Accordingly, incisions were made following the sequence of numbers shown in figures $2 \mathrm{~A}$ and $2 \mathrm{~B}$ : from ( 1 ) the mastoid process to (2) the suprasternal notch along the anterior edge of the sternocleidomastoid muscle, (3) along the medial border of the pectoralis major muscle about a centimeter lateral to the midline, (4) to the seventh chondrosternal junction, then laterally (5) to the lateral limit of the origin of the pectoralis major muscle. The incision, then followed (6) the origin of the serratus anterior muscle to (7) the anterior margin of the latissimus dorsi muscle; it continued (8) along the anterior edge of the latissimus dorsi muscle to the crest of the ilium, then posteriorly along (9) the crest of the ilium to (10) the lateral border of the thoracodorsal aponeurosis. From this point, the incision was carried to (11) the twelfth thoracic spine and along (12) the spines of the thoracic and cervical vertebrae to (13) the skull. The skin incision was completed by following (14) the nuchal line to the mastoid process.

The trapezius and sternocleidomastoid muscles were detached from the skull; the strenoclavicular joint on each side was disarticulated; the pectoralis major and pectoralis minor muscles were separated from the thoracic wall, as were the serratus 
anterior and latissimus dorsi muscles. The latter muscle was also detached from the crest of the ilium and the thoracodorsal aponeurosis. The trapezius and rhomboid muscles were separated from the vertebral column. The levator scapulae muscle was detached from the cervical transverse processes, and the omohyoid muscle was cut at the anterior margin of the sternocleidomastoid muscle. The whole mass was then separated along the loose shearing plane next to the thoracic and abdominal walls. Finally, the brachial plexus and axillary artery and vein were separated at the outer margin of the first rib. Through these dissection procedures, the two shoulder masses were entirely separated from the trunk (fig. $2 \mathrm{~A}, \mathrm{~B}, \mathrm{C}, \mathrm{C}^{\prime}$ and D).

After removal of the two shoulder masses, the remaining integument on the trunk consisted of : (1) a continuous covering of the skull vault and face above and anterior to the nuchal line and mastoid processes; (2) a v-shaped area between the sternocleidomastoid muscles that continued downward as a narrow strip anterior to the sternum; (3) a larger covering overlying the rectus sheath, the lateral abdominal muscles, the groin, genitalia, perineum, medial buttock region, and sacrum; and (4) a triangular sheet of integument over the thoracodorsal aponeurosis that converged on the apex of the spine of the vertebra T-12.

It was essential that the detached shoulder masses, which consisted partly of semi-rigid tissues, retain their natural shapes during the procedures intended to locate the center of gravity of each mass and determine the period of oscillation of each part when considered as a pendulum. Accordingly, it was necessary to freeze these parts rigidly in the shape they had while in the trunk. A plaster of paris mold was therefore made of each side of the trunk, completely overlapping each shoulder mass, before the removal of these parts. The detached masses were later fitted into these molds and packed with dry ice; upon removal, the frozen parts retained their original shapes (fig. $2 \mathrm{C}$ and $\mathrm{C}^{\prime}$ ).

After removal of the shoulder masses, the remaining trunk (fig. $2 \mathrm{D}, \mathrm{t} u \mathrm{u} \mathrm{w}$ ) was separated into three smaller sections: head-with-neck ( $\mathrm{t} \mathrm{u}$ ), thorax (v) and abdominopelvic segment ( $w$ ). Thus, the head-with-neck composite (fig. 2E) was cut from the trunk (1) along a plane that coincided with the upper borders of the first rib, (2) by disarticulating the joints between vertebrae $C-7$ and $T-1$, and (3) by severing the remaining soft tissues at the same level (fig. $2 \mathrm{D}, \mathrm{x}-\mathrm{x}$ ). The thorax (fig. 2F) was separated from the lower trunk (1) by using blunt dissection between the peritoneum and the lower surface of the diaphragm, (2) by disarticulating the column between T-12 and L-1, and (3) by severing the deep muscles of the back at the same level (fig. 2D, Y-Y). The abdominopelvic segment (fig. $2 \mathrm{G}$ ) was the remaining mass of the trunk.

Finally, after measurements on the composite, the head-with-neck segment $(t \mathrm{u}$ ) was separated (fig. $2, \mathrm{H}, \mathrm{I}$ ) into the head proper $(\mathrm{t})$ and the neck $(\mathrm{u})$. The neck, it will be recalled, lacks sternocleidomastoid and trapezius muscles and the overlying integument. The procedure adopted was simply (1) the making of a transverse cut just below the hyoid level and across the neck viscera to the level of the prevertebral fascia; (2) blunt dissection between the neck viscera anteriorly and the prevertebral fascia posteriorly to the level of the skull base; (3) severing the deep muscles of the neck from the occipital and temporal bones; and (4) separation of the skull from the column by disarticulating the atlantooccipital joint and by cutting the longus and rectus muscles. The head so-defined is both anatomically and mechanically correct, in contrast to the simple straight cut of Harless, Meeh, and Braune and Fischer. Measurements were made of the head segment alone but not of the neck alone, since measurements on a block of tissues representing cervical vertebrae, deep back muscles, and the neck viscera would have little meaning.

Although considerable tissue retraction after cutting across the limbs was noted by Harless who adjusted for this by stretching the skin and stitching it over the cut ends, this was not a significant feature for either the unpreserved or preserved material of this study. Whether it was the time interval after death, the freezing of 
joints prior to sawing or a generally older group of subjects, some factor or combination of factors must have reduced tissue elasticity.

Linear measurements. Linear measurements of the body parts were made in the metric system, using a standard anthropometer for larger measurements, a spread- ing caliper for measurements of parts of intermediate size, and a sliding caliper for measurements of small parts (hand and foot). Table 1 shows the end-points used for caliper measurements relating to the limb segments (links) after they were separated into units. The same instruments were also used in measurements

TABLE 1

End points for calipering link lengths and related dimensions

\begin{tabular}{ccc}
\hline Body part & $\begin{array}{c}\text { Superior (proximal) } \\
\text { end point }\end{array}$ & $\begin{array}{c}\text { Inferior (distal) } \\
\text { end point }\end{array}$
\end{tabular}

1 Shoulder

2 Arm

(a) same as $1 b$ (distal face of cut)

3 Forearm

4 Hand

5 Thigh

6 Shank

7 Foot

8 Entire head and trunk

9 Head and neck

10 Thorax

11 Abdomino-pelvic segment

12 Transhumeral width

13 Transacetabular width

14 Hip-to-shoulder height (a) same as $3 b$ (distal surface of cut)

(a) same as $5 b$ (distal face of cut)

(a) same as end point $2 b$ (distal face of cut)

(a) center of curvature of femoral head

(a) same as 6b (distal face of cut)

(a) vertex of head

(a) vertex of head

(a) midpoint of disc tissue at superior face of centrum of vertebra $T-1$

(a) midpoint of disc tissue, superior face of centrum of vertebra $L-1$

Widths and a Height - End Points

Span between points $1 \mathrm{~b}$ of right and left sides

Span between centers of femoral heads of right and left sides, measured after removal of lower limbs

Vertical distance between lines 12 and 13 (b) center of curvature of humeral head (proximal surface of cut that bisects midrange joint angle)

(b) junction, transverse axis of trochlea of humerus at narrowest cross section of ulnar articulation

(b) center of curvature of proximal end of capitate bone (proximal face of cut)

(b) proximal interphalangeal knuckle of finger II, position of rest

(b) middle of a line through the center of curvature of the posterior aspect of the two femoral condyles (proximal face of cut)

(b) center of the area of the cut body of the talus (proximal face of cut)

(b) tip of great toe

(b) midpoint of the transacetabular line

(b) center of cut intervertebral disc at lower face of centrum of vertebra $\mathrm{C}-7$

(b) midpoint of disc tissue of inferior face of centrum of vertebra T-12

(b) same as $8 b$ 
relating to center of gravity. All unitary segments were measured in this way.

As stated earlier, anterior, posterior and left side photographs had been made of the body as suspended by tongs. The camera, equipped with a ten inch lens, was at a standard distance at hip height and a $5 \times 7$ film was exposed in a triple back to show each view of the body at a height of four and one-half to four and three-fourths + inches on the ground glass; a measuring scale and plumb line were included in the field of view. After enlarged positives were made of the views, calipered stature and link dimensions could be scaled off on the photographs with the links meeting at best estimated joint center positions. Each side was a check on the other. Several additional dimensions on the photographs were scaled off and corrected using a reduction factor based on cadaver and photograph size. These gave enough secondary measurements to allow the outline of figure 3 to be drawn. Apart from the outline, figure 3 is a stick figure in which the lengths are shown as a percentage of stature.

Location, centers of mass. Both suspension and balancing methods were used for locating the center of mass (gravity) of the body parts; the method was varied with the purpose of the measurement and with the part studied. Figure 4A shows a suspension system, roughly comparable with that of Braune and Fischer, (1889), with two plumb lines for sighting. This system was used alone for such nonlinear parts as the head (fig. 4B), hand, shoulder, and thorax; successive suspensions from at least three widely separated points permitted the center of mass to be located at a single point in space, that is, the intersection point of three planes.

For elongate limb segments, a balancing plate was used as shown in figure $4 \mathrm{C}$. This system permitted one to locate a transverse plane through the center of mass, relative to the length of the part. The plane of balance was identified by stretching a thread over the specimen from balance point to balance point, and the line of thread contact was marked on

Fig. 3 Link figure with mean dimensions of each link stated in terms of percentage of statures.

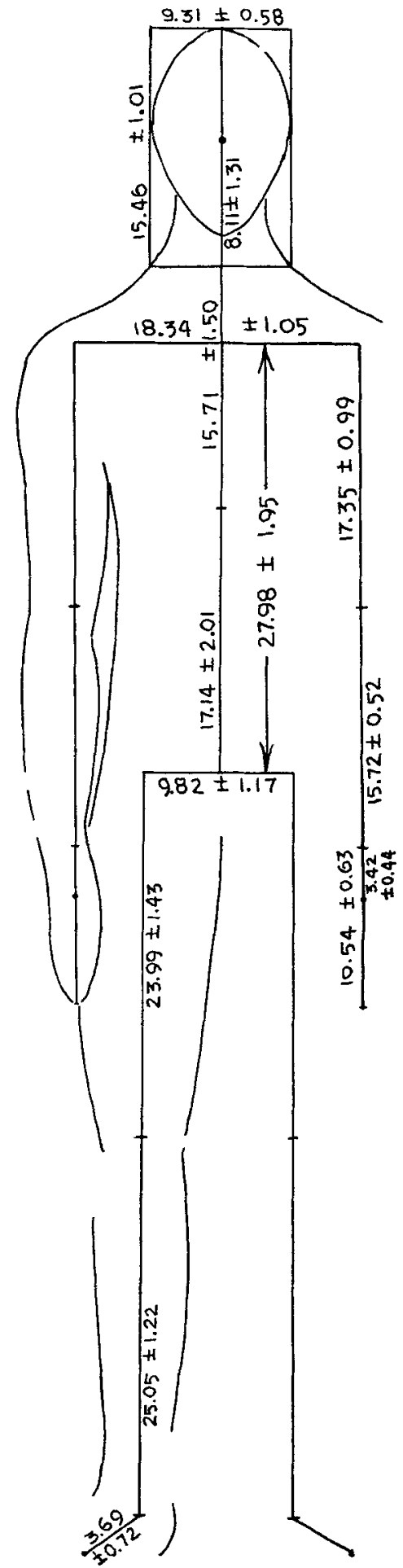

Figure 3 

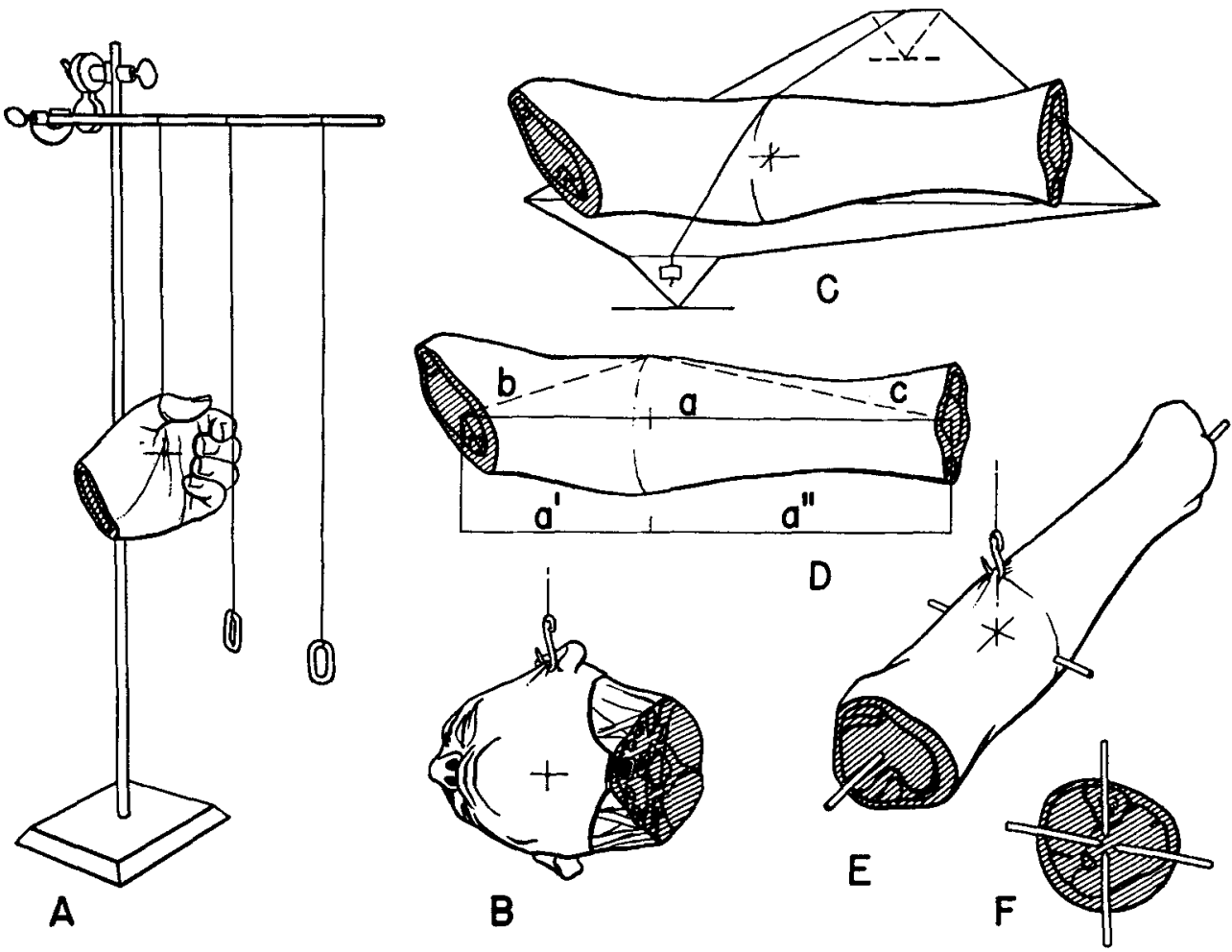

Fig. 4A Method for locating center of mass on hands (or feet and thorax) by suspension from different points, sighting across plumb lines, and marking. B, Special suspension method for the head, keeping the sagittal plane horizontal. $C$, Special sheet metal balance plate for locating center of mass of the long limb segments and the abdominopelvic complex. D, Geometry for determining the correct ratio of lengths $\left(a^{\prime}\right)$, or $\left(a^{\prime \prime}\right)$, to (a) when caliper measurements relate to (a), (b), and (c). E, Suspension of long limb segments so that drill holes and dowels will intersect at the center of mass of a cross section. F, A sawcut section through a limb segment at a plane marked by dowels which point toward the center of mass to be located anatomically.

the skin. Then the part was rotated about its longitudinal axis, balanced, and marked again; the encircling line clearly demarcated the transverse level of the center of mass for that segment.

Suspension of the various limb segments endwise from the joint centers confirmed Braune and Fischer's comment (1889) that segment centers of mass fall on or near a line interconnecting joint centers. Since the plane of balance was marked with a skin pencil on the surface of a segment, however, the relative distance of the center of mass from the two ends along this straight line was not immediately available. The following procedure was required to obtain this information for each part (fig. 4D): a caliper measurement (distance a) was made spanning from end to end of the segment; two more measurements ( $b$ and $c$ ) were made, each from one end to a point on the skin surface at the transverse level of the center of mass, that is, at the skin-pencil mark. These three caliper measurements $(a, b$, and $c)$, when plotted, made up the sides of a flat scalene triangle. A calculation involving simple geometrical ratios gave the proper value; thus the corrected distance of the center of mass from the proximal end of the segment $\left(a^{\prime}\right)$ was:

$$
a^{\prime}=\frac{b^{2}-c^{2}+a^{2}}{2 a} \text {. }
$$

After all other measurements were made, the location of the center of mass of each limb segment, relative to anatomical landmarks, was determined by the fol- 
lowing procedure. Each part was refrozen and, if necessary, rebalanced so that the next encircling line at the plane of balance could be marked again. Next, by either successive suspensions or through successive balancings, two or three diameters through the encircling mark and the center of mass were defined. After end points of two or three diameters had been marked, drill holes were then made into the part along the marked diameters, and pointed one-fourth inch dowels were driven into the holes. The center of mass was then transected by a sawcut in the plane of the sticks. A detailed anatomical study of the cut surface, together with some dissection of the part when the tissues thawed, permitted an exact anatomical location of the center of mass relative to muscles, tendons, and bones of the segment.

To locate the center of mass of the headwith-neck segment anatomically, a special technique was followed. The mass was suspended from several trial points on the skin until the head hung with its sagittal plane horizontally (fig. 4B). After proper suspension points for both right and left sides were found, lead-headed tacks were pushed into the skin to mark these points. Lateral $x$-ray films were then made of the segment to locate its center of mass; this lay at the point where a line between the lead-headed tacks intersected the plane of the midsagittal bony anatomy. Alternately, drill holes were made at both suspension points, each aiming towards the other, and a pointed dowel was driven through the whole width of the head; a sagittal sawcut showed the cut dowel which marked the location of the center of mass. In two instances, the center of mass of the head alone (t) was also determined. The x-ray method was advantageous in that it required neither sagittal sawcuts nor drill holes, and parts could remain intact.

Weighing techniques. For those body parts with a mass of less than $20 \mathrm{~kg}$ critical weighings were made on a solution balance calibrated in grams and accurate with any combination of counterbalancing weights to within one or two grams - less than $0.5 \%$ error for the smallest part weighed. Larger masses, such as those of the total trunk, or abdominopelvic mass, were measured to the nearest quarterpound on a $300 \mathrm{lb}$. av. Fairbanks grain scale, then expressed in metric units. Total body mass was measured by placing the body on two bathroom scales; data were corrected and converted to metric units later, A measurement error of within $\pm 1.0 \%$ may be assumed for the two latter techniques.

Volumetric measurements. All determinations of volume were made using a procedure of double weighings based on Archimides's principal of water displacement. Thus, the difference between the weight of the part in air and the weight submerged in water represented the mass of water displaced; this value, assuming a water density of 1.0 , gave the corresponding volume of the part. The heavier body parts were encircled with cord, lifted with block and tackle, and lowered into a cylindrical tank of water. If the part contained air, a lead weight of known mass and volume was attached to assure submersion; this extra factor was allowed for in the calcualtions. After the part was submerged, it was disconnected from the block and tackle and suspended from a $15 \mathrm{~kg}$ Chatillon autopsy spring scale previously attached to the block and tackle.

Lighter body parts were weighed in air attached by a cord and submerged by hand and then connected directly to the scales. These submerged weighings took only a moment or two and the parts were immediately drained and dried; thus later weighings were not noticeably contaminated through absorbing water in earlier immersions. It was critically important, however, following each freezing and sawing phase that the parts be entirely thawed, to avoid volume measurements that would be too high because of low density ice in the tissues. Weighings under water were not as accurate for the smaller parts, such as the hands, as for those of larger size. In retrospect a method involving the spillover and weighing of displaced water would have been preferable for volumes of a liter or less.

As the larger segments (head and trunk, abdominopelvic segment, thigh) drained after the immersion, they sometimes noticeably dripped blood. However, reweighings before and after immersion indicated 
that any errors caused by immersion and blood loss, were negligible.

For many of the weighings and volumetric measurements, however, three separate determinations on different segment composites could be used as checks on the size of the component parts and these values could be averaged. With regard to the hand, for instance, the records included: (1) a direct measurement of mass (and volume) for the hand $(p)$ as a separate segment, (2) an indirect determination derived from the value for the entire upper-limb ( $p q r$ ) minus the values for the forearm (q) and arm ( $r$ ), and (3) an indirect value calculated from data for forearm-with-hand ( $q$ p) minus the forearm (q). Similarly, one direct and two substraction values for mass (and for volume) were possible for the forearm (q) and for the arm (r). Analogous calculations were possible with each of the lower-limb segments also, giving three values of mass (or volume) for each.

In the midbody section, similar determinations were possible for both masses and volumes; thus shoulders (s) were measured separately, but the trunk-minusshoulders mass ( $t \mathrm{u} \mathrm{v} \mathrm{w}$ ) could also be subtracted from the trunk-minus-limbs

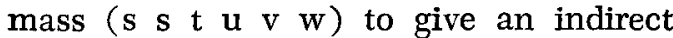
value for the right-plus-left-shoulder mass. Using comparable additions and substractions, it was possible to supplement a direct measurement with indirect measurements for the mass and volume of both shoulders together $(s+s)$, of the initial head and trunk part ( $\mathrm{s} \mathrm{t} \mathbf{u} \mathrm{v} \mathbf{w}$ ), and of the shoulderless head and trunk $(t \mathbf{u ~ v} w)$. Additionally, the mass (and volume) of each of the separate axial units, the head and neck ( $t u$ ), thorax $(v)$, abdominopelvic complex (w), could be both measured directly and subtracted from the $\mathrm{t}-\mathrm{u}-\mathrm{v}-\mathrm{w}$ mass (and volume) giving indirect values for each component. These multiple mass and volume determinations were of special value in working over data on body segments long since measured and discarded.

Density. The density or specific gravity of each part for each specimen was simply the mathematical quotient of mass divided by volume.

Tissue density. Following the location of segment centers of mass anatomically and before material was discarded, each segment was again weighed, then it was dissected into (1) skin and subcutaneous tissues, (2) muscle and associated tissues (including fasciae, tendons, blood vessels, and nerves), and ( 3 ) bone and joint. Each of these components was weighed and then it was immersed in a graduate cylinder containing a measured amount of water - bubbles were avoided. The mass divided by the volume of water displaced gave the density of the component.

\section{RESULTS}

The anatomical end points used in this study for the measurements of link lengths and the locations of the center of mass are given in table 1 . The dimensions of the various links calipered in the Michigan cadaver material as well as the Braune and Fischer data can be found in table 2 . These are expressed in centimeters and also as per cent of total stature. Table 3 lists the location of segment centers of

TABLE 2

Link dimensions of cadavers in relation to stature

\begin{tabular}{|c|c|c|c|c|c|}
\hline & \multicolumn{3}{|c|}{ Michigan data } & \multicolumn{2}{|c|}{ Leipzig data (Braune and Fischer) } \\
\hline & & $\mathrm{cm}$ & $\%$ & $\mathrm{~cm}$ & $\%$ \\
\hline Thigh link & 40.56 & $\pm 2.42(18)$ & $23.99 \pm 1.43$ & $43.32 \pm 1.21(10)$ & $24.26 \pm 0.74$ \\
\hline Shank link & 42.36 & $\pm 2.07(18)$ & $25.05 \pm 1.22$ & $40.55 \pm 1.43(10)$ & $24.72 \pm 0.87$ \\
\hline Foot link & 6.23 & $\pm 1.22(18)$ & $3.694 \pm 0.720$ & & \\
\hline Lumbocoxal link & 28.99 & $\pm 3.40(8)$ & $17.14 \pm 2.01$ & & \\
\hline Thoracic link & 26.57 & $\pm 2.54(8)$ & $15.71 \pm 1.50$ & & \\
\hline Craniocervical link & 13.71 & $\pm 2.21(8)$ & $8.11 \pm 1.31$ & & $(10.6)^{1}$ \\
\hline Arm link & 29.34 & $\pm 1.67(18)$ & $17.35 \pm 0.99$ & $29.41 \pm 1.12(6)$ & $17.93 \pm 0.68$ \\
\hline Forearm link & 26.58 & $\pm 0.87(18)$ & $15.72 \pm 0.52$ & $27.42 \pm 1.25(4)$ & $16.72 \pm 0.76$ \\
\hline Hand link & 5.777 & $\pm 0.745(18)$ & $3.422 \pm 0.441$ & $5.38 \pm 0.33(6)$ & $3.28 \pm 0.20$ \\
\hline Transpelvic & 16.32 & $\pm 1.79(19)$ & $9.82 \pm 1.17(19)$ & $16.73 \pm 0.48(3)$ & $10.20 \pm 0.29$ \\
\hline
\end{tabular}

1 Only one measurement available. 
TABLE 3

Distance between proximal end point and segment center of mass

\begin{tabular}{lcc}
\hline & Michigan data & $\begin{array}{c}\text { Leipzig data } \\
\text { (Braune and Fischer) }\end{array}$ \\
\hline Thigh & $\%$ of link & \% of link \\
Shank & $42.78 \pm 2.05(18)$ & $43.68 \pm 2.50(10)$ \\
Foot & $42.64 \pm 2.32(18)$ & $42.14 \pm 0.99(10)$ \\
Lumbocoxal segment & 100.00 & \\
Thorax & $54.85 \pm 7.46(8)$ & \\
Arm & $66.10 \pm 6.39(8)$ & $45.90 \pm 2.38(10)$ \\
Forearm & $43.74 \pm 3.03(18)$ & $42.12 \pm 1.07(6)$ \\
Hand & $42.93 \pm 2.13(18)$ & 100.00 \\
\hline
\end{tabular}

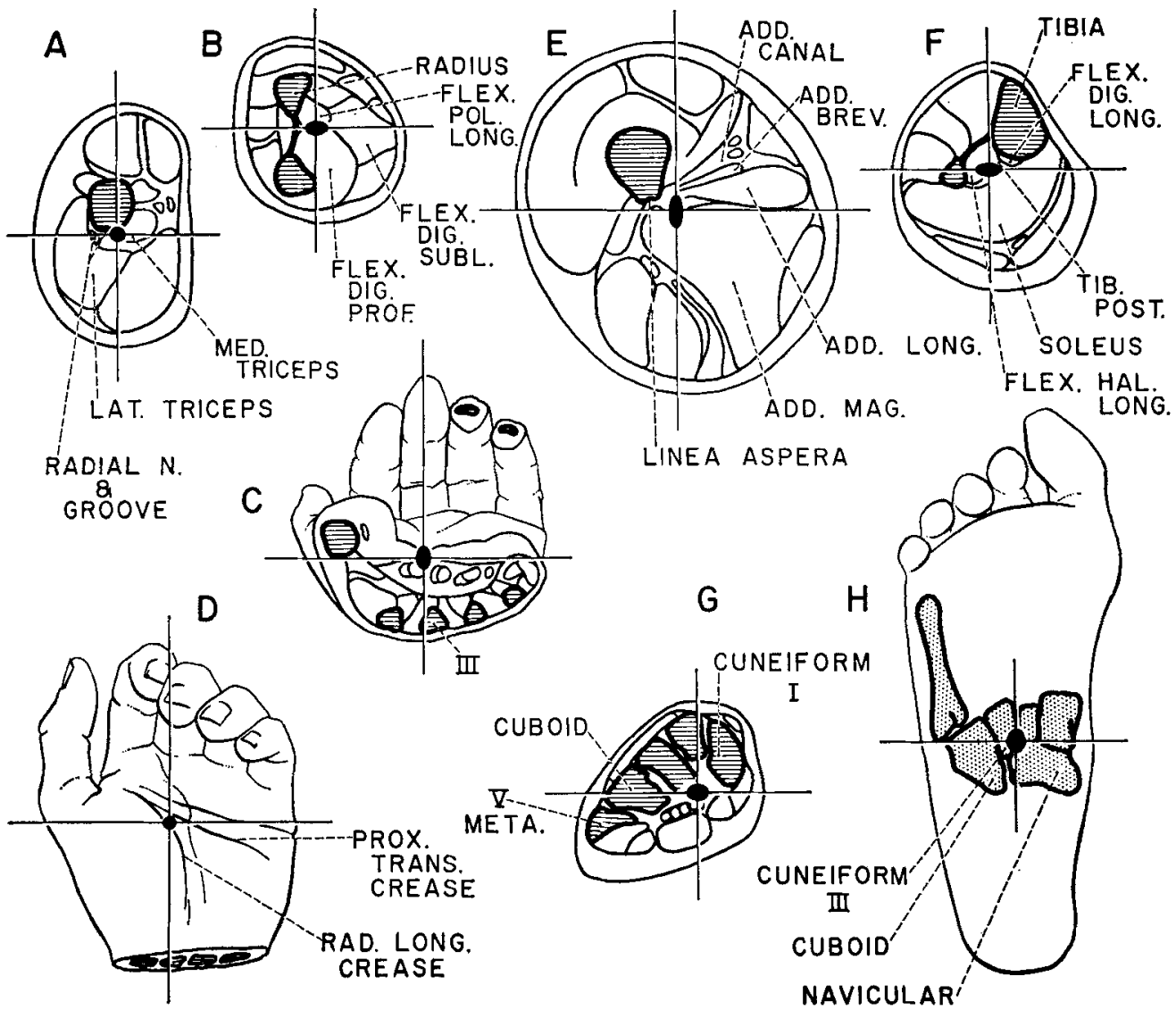

Fig. 5 Anatomical locations of center of mass in the limb segments. The relative heights and widths of the black spots that are centered over the average location of the center of mass reflect the relative variability in the two directions; each height and width correspond with the plus and minus mean deviations of position of the center of mass. The bones in the section are shaded and the more relevant muscles and other landmarks are labeled. A, Arm section. B, Section through the forearm segment. $C$ and $D$, Center of mass location in the hand. $E$, Center of mass location in the thigh segment. F, Location in the leg. $G$ and H, Location of center of mass of the foot segment. 
mass measured from the proximal end points and given as per cent of the total link length. The anatomical locations of the average centers of mass are shown in figures 5 and 6 . The elliptical shape of the loci is to represent the mean deviation of these centers. The mean mass and per cent of total mass of body segments for the Michigan and the Leipzig cadavers are listed in table 4 . The mean volume of our cadaver segments and their ratio to total body volume are in table 5 . In seven bodies the limb segments were further dissected to determine the proportion of skin and fascia, muscle, and bone. These results are shown in table 6 as per cent of
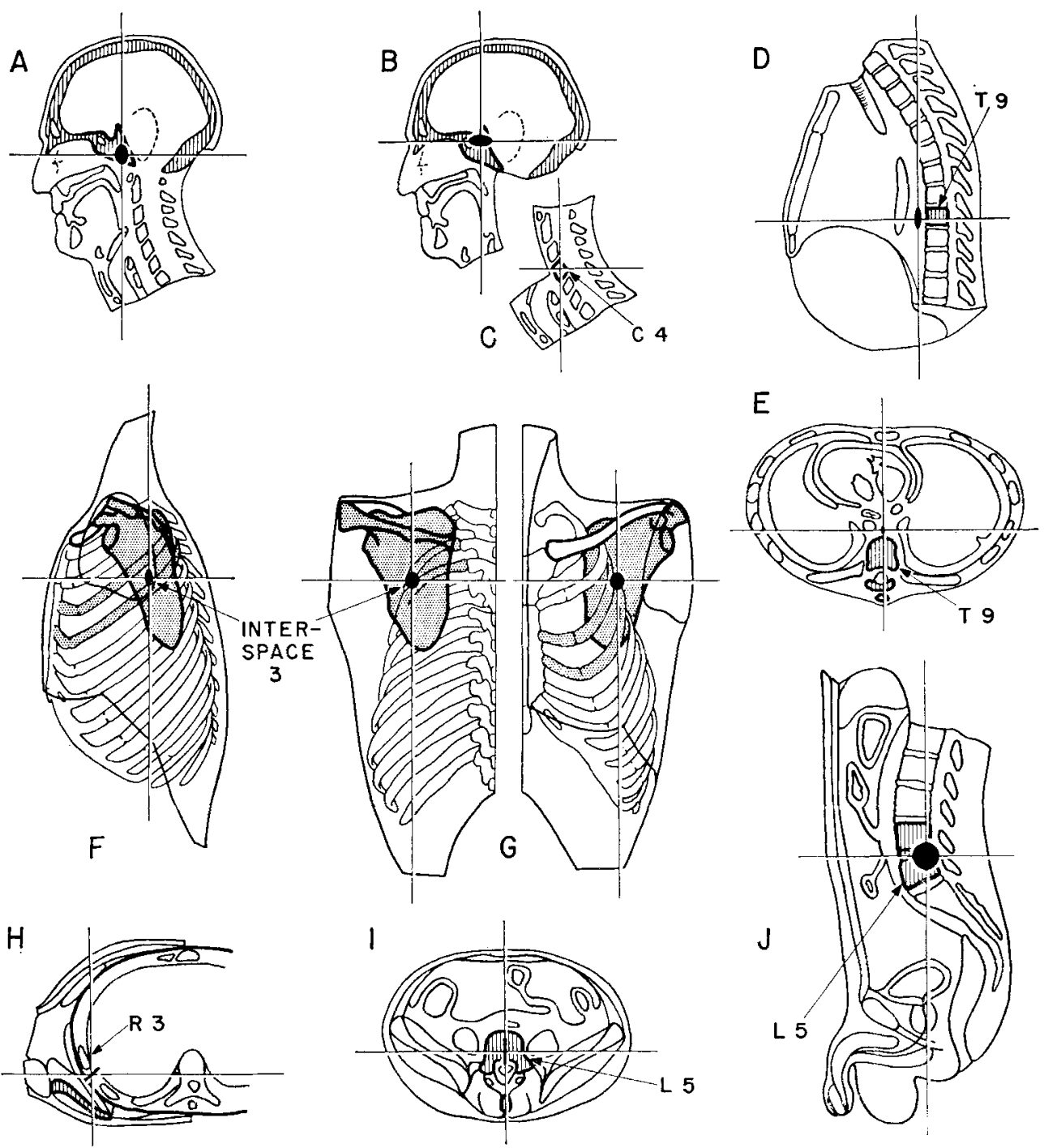

Fig. 6 Center of mass location in segments of the head and trunk. A, Location in the head and neck; dotted line, ear outline. $B$ and $C$, Locations in the head alone and in the neck. D and $E$, Center of mass of the thorax anterior to vertebral body T-9. F, G, and H, Center of mass of shoulder segment below rib 3. I and J, Abdominopelvic center of mass in the vertebral body of L-5. The relative vertical and horizontal dimensions of the black ellipse at the center of mass of the segment indicates the variability of position in the cardinal axes of the part (cf. fig. 5 ). 
TABLE 4

Mean weights of male cadaver segments and ratio to total body weight

\begin{tabular}{|c|c|c|c|c|c|c|}
\hline \multirow[b]{3}{*}{$\begin{array}{l}\text { Total body } \\
\text { weight }\end{array}$} & \multicolumn{3}{|c|}{ Michigan data (Dempster) } & \multicolumn{3}{|c|}{ Leipzig data (Braune and Fischer) } \\
\hline & \multicolumn{2}{|c|}{ Mean weights (gm) } & \multirow{2}{*}{$\begin{array}{c}\% \text { of 'Total } \\
100\end{array}$} & \multicolumn{2}{|c|}{ Mean weights (gm) } & \multirow[t]{2}{*}{$\%$ of Total } \\
\hline & 61190 & $\pm 8137 \quad(7)$ & & 58895 & (5) & \\
\hline $\begin{array}{l}\text { Head and } \\
\text { trunk }\end{array}$ & 34637 & $\pm 5607 \quad(18)$ & $56.34 \pm 2.45(6)$ & 30824 & (5) & $52.21 \pm 2.97(5)$ \\
\hline $\begin{array}{l}\text { Head and } \\
\text { trunk minus } \\
\text { shoulders }\end{array}$ & 28077 & $\pm 3994 \quad(18)$ & $46.02 \pm 2.239(5)$ & & & \\
\hline $\begin{array}{l}\text { Head and } \\
\text { neck }\end{array}$ & 5119 & $\pm 838(16)$ & $7.92 \pm 0.85(7)$ & & & \\
\hline Shoulders & $3401=$ & \pm 843 (34) & $5.27 \pm 0.546(14)$ & & & \\
\hline Thorax & 7669 & \pm 2270 & $10.97 \pm 1.521(7)$ & & & \\
\hline $\begin{array}{l}\text { Abdomino- } \\
\text { pelvic } \\
\text { headless } \\
\text { trunk }\end{array}$ & 16318 & $\pm 2505 \quad(18)$ & $26.39 \pm 2.908(7)$ & & & \\
\hline Arm & 1636 & \pm 350 & $2.64 \pm 0.294(14)$ & $2017 \pm 406$ & (22) & $3.167 \pm 0.27(10)$ \\
\hline Forearm & 947 & \pm 199 & $1.531 \pm 0.166(14)$ & $1342 \pm 242$ & $(18)$ & $2.087 \pm 0.245(6)$ \\
\hline Hand & 378.3 & $\pm 71.7(42)$ & $0.612 \pm 0.058(14)$ & $536.1 \pm 84.4$ & (18) & $0.833 \pm 0.045(6)$ \\
\hline Thigh & 609.6 & \pm 985 (41) & $10.008 \pm 1.197(14)$ & $6632 \pm 783$ & (22) & $10.924 \pm 0.769(10)$ \\
\hline Shank & 2852 & \pm 695 (41) & $4.612 \pm 0.534(14)$ & $2924 \pm 379$ & (22) & $4.680 \pm 0.353(10)$ \\
\hline Foot & 884 & \pm 178 & $1.431 \pm 0.142(14)$ & $1072 \pm 106$ & (22) & $1.765 \pm 0.194(10)$ \\
\hline
\end{tabular}

TABLE 5

Mean volumes of male cadaver segments and ratio to body volume

\begin{tabular}{lrc}
\hline & \multicolumn{2}{c}{ Michigan data (Dempster) } \\
\cline { 2 - 3 } & \multicolumn{1}{c}{ Volume $\left(\mathrm{cm}^{3}\right)$} & Ratio \\
\hline Total body volume & $61,190 \pm 8137$ & $54.877 \pm 2.280(6)$ \\
Head and trunk & $33,970 \pm 4570(18)$ & $45.545 \pm 1.377(5)$ \\
Head and trunk minus shoulders & $27,815 \pm 3687(18)$ & \\
Head and neck & $4,508 \pm 818(14)$ & $7.178 \pm 0.709(7)$ \\
Shoulders & $3,172 \pm 919(34)$ & $5.063 \pm 0.563(14)$ \\
Thorax & $7,752 \pm 1978(16)$ & $12.109 \pm 1.370(7)$ \\
Abdominopelvic mass & $15,854 \pm 2366(18)$ & $26.274 \pm 3.361(7)$ \\
Arm & $1,533 \pm 332(42)$ & $2.439 \pm 0.294(14)$ \\
Forearm & $857 \pm 180(42)$ & $1.531 \pm 0.167(14)$ \\
Hand & $342.7 \pm 73.8(42)$ & $0.612 \pm 0.057(14)$ \\
Thigh & $5.865 \pm 969(41)$ & $9.588 \pm 1.142(14)$ \\
Shank & $2.643 \pm 654(41)$ & $4.221 \pm 0.502(14)$ \\
Foot & $833 \pm 174(41)$ & $1.294 \pm 0.143(14)$ \\
\hline
\end{tabular}

1 Total body volume equals weight divided by density of 1.0 . 
total weight. The data from a similar study of the shoulder segment of three of the bodies are also tabulated in this table. Finally, the average density of body segments for our cadaver material and the Harless data are presented in table 7 . All of the tabulated values include the standard deviation and the sample numbers are given in parentheses.

\section{DISCUSSION}

From the descriptions of the techniques used by earlier workers, it is evident that this data, if it is to be used, cannot be amalgamated for comparison but must, rather, be interpreted in the light of the investigator's individual data gathering idiosyncrasies. The very small samples, peculiarities of determining segments, disarticulation, loss of body fluids, position of limbs, etc. have marked effects on body constant values. The measurement of segments from the proximal to the distal extremity of the bone is not the value re- quired for link length. This dimension must be based on the mean interaxial distance of the segment. Hence, joints should not be disarticulated. Measurements based on surface landmarks must be understood, equilibrated, or standardized. We have attempted to identify superficial, palpable landmarks to locate link endpoints which can be duplicated in further investigations by later workers on cadaver or living material. Similarly, it is equally important to use a standardized, if nevertheless arbitrary, limb position. Obviously, the soft tissues overlying articulations will share their mass with adjacent links; the degree to which they contribute to the links will vary with the degrees of freedom and position exhibited by the joint. The fluidity of this mass distribution will effect not only mass values for links but the locations of segment centers of gravity and other body constants as well. Our efforts were directed toward establishing mid-

TABLE 6

Mass in per cent of total weight

\begin{tabular}{lccc}
\hline & Skin and fascia & Muscle & Bone \\
\hline Thigh & $29.0 \pm 3.31(14)$ & $59.6 \pm 2.81(14)$ & $11.5 \pm 1.78(14)$ \\
Shank & $22.2 \pm 2.98(14)$ & $45.6 \pm 2.85(14)$ & $32.3 \pm 2.56(14)$ \\
Foot & $29.2 \pm 4.30(14)$ & $20.3 \pm 4.25(14)$ & $50.7 \pm 7.35(14)$ \\
Arm & $26.0 \pm 3.85(14)$ & $56.8 \pm 4.74(14)$ & $18.0 \pm 1.61(14)$ \\
Forearm & $18.7 \pm 4.25(14)$ & $53.2 \pm 4.90(14)$ & $28.2 \pm 3.99(14)$ \\
Hand & $28.4 \pm 3.04(13)$ & $27.6 \pm 2.98(13)$ & $44.0 \pm 3.27(13)$ \\
Shoulders (left side only) & $36.5 \pm \mathbf{3 . 3 4 ( 6 )}$ & $53.9 \pm 4.09(6)$ & $9.6 \pm 3.76(6)$ \\
\hline
\end{tabular}

TABLE 7

Average density of body segments of cadavers ${ }^{1}$

\begin{tabular}{lcc} 
& $\begin{array}{c}\text { Michigan data } \\
\text { (Dempstex) }\end{array}$ & Harless data \\
\hline Whole body ${ }^{2}$ & Density $\left(\mathrm{gm} / \mathrm{cm}^{3}\right)$ & Density \\
Head and trunk & 1.003 & \\
Trunk minus shoulders & $1.0138 \pm 0.0260(18)$ & \\
Head and neck & $1.0088 \pm 0.0319(18)$ & $1.0851(1)^{3}$ \\
Shoulders & $1.1708 \pm 0.1825(14)$ & \\
Thorax & $1.0925 \pm 0.1318(34)$ & \\
Abdominopelvic mass & $0.9573 \pm 0.1284(16)$ & $1.0887 \pm 0.0036(5)$ \\
Arm & $1.0297 \pm 0.0424(18)$ & $1.1097 \pm 0.0040(5)$ \\
Forearm & $1.0676 \pm 0.0266(42)$ & $1.1126 \pm 0.0064(5)$ \\
Hand & $1.1015 \pm 0.0430(42)$ & $1.0685 \pm 0.0149(6)$ \\
Thigh & $1.0696 \pm 0.3491(42)$ & $1.1000 \pm 0.0217(6)$ \\
Shank & $1.0401 \pm 0.0170(41)$ & $1.0893 \pm 0.0089(6)$ \\
Foot & $1.0789 \pm 0.0288(41)$ &
\end{tabular}

1 Mass in aix divided by volume.

2 From literature.

3 Head alone. 
range joint positions which could be identified, duplicated, and described.

In considering the Michigan data, we must remember that we are dealing with a sample which was older and below average stature and weight when compared with the national average. Nor do we have information on the body constants of infants, children, young adults, and females. These values also vary with body type. We did analyze the amount of bone, muscle, skin and fascia in several specimens but much additional information is needed to determine the relationship which exists between body physique and the distribution of mass as well as the center of mass. Physiological status also effects the distribution of volume and mass. The exact degree of this effect is another area of investigation.

\section{LITERATURE CITED}

Barter, J. T. 1957 Estimation of the mass of body segments. WADC Technical Report 57260.

Bernstein, N. 1935 Untersuchungen über die Biodynamik des Ganges des normalen erwachsenen Mannes. Inst. Exper. Med. d. Soviet Union, Moscow. 243 pp. (In Russian; German summary)

Braune, W., and $O$. Fischer 1889 über der Schwerpunkt des Menschlichen Körpers mit Rücksucht auf die Ausrüstung des Deutschen Infanteristen. Abhandl. d. Kl. sächs. Ges. Wiss. Math. Phys. Kl., 15 (7): 561-672.

1892 Bestimmung der Trägheitsmomente des menschlichen Körpers und seiner Glieder. Abhandl. d. Kl. sächs. Ges. Wiss. Math. Phys. Kl., 18 (8): 409-492.

Contini, R., R. J. Drillis and M. Bluestein 1963 Determination of body segment parameters. Human Factors, 5: 493-504.

Dempster, W. T. 1955a Space requirements of the seated operator. WADC Technical Report 55-159.

1955b The anthropometry of body action. Ann. N. Y. Acad. Sci., 63: 559-585.

1961 Free-body diagrams as an approach to the mechanics of human posture and motion. In F. G. Evans et al., Biomechanical studies of the musculo-skeletal system. Charles C Thomas, Springfield, Ill. Chap. 5, 81-135.

1965 Mechanisms of shoulder move. ment. Arch. Phys. Med. \& Rehabilitation, 46: 49-70.

Dempster, W. T,, L. A. Sherr and J. G. Priest 1964 Conversion scales for estimating humeral and femoral lengths and the lengths of functional segments in the limbs of American caucasoid males. Human Biol., 36: 246-262.

Duggar, B. C. 1962 The center of gravity of the human body. Human Factors, 4: 131-148.
Elftman, H. 1939 The Rotation of the Body in Walking. Arbeitsphysiol., 10 (5): 477-484.

Fischer, O. 1892 Ein zweiter Mechanismus zur Bestimmung der Lage des Schwerpunktes eines Systems von in bellebiger Weise durch Gelenke mit einander verbundenen Körpern; Einige Gelenkmechanismen; Mechanismus zur Bestimmung der Lage des Schwerpunktes des menschlichen Körpers und seiner Teile. Katalog math. u. math.-phys. Modelle, Apparate u. Instrumente. 100-104, 350-359.

1904 Der Gang des Menschen. Abh. d. Math.-Phys. Cl. d. k. Sächs. Gesellsch. d. Wiss., 28: 319-418.

1906 Theoretische Grundlagen fur eine Mechanik der lebenden Körper. B. G. Teubner, Leipzig u. Berlin, 372 pp.

Fujikawa, K. 1963 The center of gravity in the parts of the human body. Okajimas Fol. Anat. Jap., 39: 117-126.

Harless, E. 1857 Lehrbuch der plastischen Anatomie, enthaltend die Gesetze für organische Bildung und künstlerische Darstellung der menschlichen Gestalt im Allgemeinen und in den einzelnen Situationen. 2 vol., 170 pp., 180 pp., Ebner u. Seubert, Stuttgart.

1860 Die statischen Momente der menschlichen Gliedmassen. Abhandl. d k. bayer. Akad. d. Wissensch., 8: 71-96, 259-294.

Jones, F. W. 1920 The principles of anatomy as seen in the hand. P. Blakiston's Son, Phila., $325 \mathrm{pp}$.

Krause, C. F. T. 1843 Handbuch der menschlichen anatomie. Hahn'schon Hofbuchandlung, Hanover, $1274 \mathrm{pp}$.

Krogman, W. M., and F. E. Johnston 1963 Human mechanics: four monographs abridged. Tech. Doc. Rep. AMRL-TDR-63-123.

Meeh, C. 1895 Volummessungen des menschlichen Körpers und seiner einzelnen Theile in den verschiedenen Altersstuten. Ztschr. f. Biol., 31: 125-147.

Meyer, G. H. 1873 Die Statik und Mechanik des Menschlichen Knochengerustes. Wilhelm Engelmann, Leipzig, 402 pp.

Sheldon, W. H., C. W. Dupertuis and E. McDermott 1954 Atlas of men. Harper \& Bros., New York, 357 pp.

Sheldon, W. H., S. S. Stevens and W. B. Tucker 1940 The varieties of human physique. Harper \& Bros., New York, 347 pp.

Spector, W. S. (ed.) 1956 Handbook of biological data. W. B. Saunders, Phila., 584 pp.

Valentin, G. G. 1850 Lehrbuch der Physiologie des Menschen. ( 2 vols. bound in 3), F. Vieweg u. Sohn, Braunschweig, 420 pp., 731 pp., 316 pp.

Vierordt, H. 1893 Anatomische, physiologische und physikalische Daten und Tabellen zum Gebrauche fur Mediciner. G. Fischer, Jena, $400 \mathrm{pp}$.

Williams, H. R., and M. Williams 1962 Biomechanics of human motion. W. B. Saunders, Phila., 147 pp.

Zook, D. E. 1932 Physical growth of boys: a study by means of water displacement. Am. J. Dis. Child., 43: 1347-1432. 